A Note on the Depiction of a Hoplite on a Sherd from Ashkelon

Author(s): Jeffrey R. Zorn

Source: Bulletin of the American Schools of Oriental Research, No. 372 (November 2014), pp. 35-38

Published by: The American Schools of Oriental Research

Stable URL: https://www.jstor.org/stable/10.5615/bullamerschoorie.372.0035

JSTOR is a not-for-profit service that helps scholars, researchers, and students discover, use, and build upon a wide range of content in a trusted digital archive. We use information technology and tools to increase productivity and facilitate new forms of scholarship. For more information about JSTOR, please contact support@jstor.org.

Your use of the JSTOR archive indicates your acceptance of the Terms \& Conditions of Use, available at https://about.jstor.org/terms

The American Schools of Oriental Research is collaborating with JSTOR to digitize, preserve and extend access to Bulletin of the American Schools of Oriental Research 


\title{
A Note on the Depiction of a Hoplite on a Sherd from Ashkelon
}

\author{
JEFFREY R. ZORN
}

\begin{abstract}
A recently published East Greek sherd from Ashkelon is said to depict a hoplite carrying a quiver against the exterior surface of his shield. Based on contemporary parallels on other Greek pottery, this brief note suggests that what is depicted is instead an interior view of the shield showing the hoplite's bent arm and hand supporting/carrying the shield.
\end{abstract}

$\mathrm{T}$

he recent publication of Ashkelon 3 (Stager, Master, and Schloen 2011) has provided a wealth of new data for conditions in the southernmost part of the Levant at the end of the Iron Age. A major section of this important publication is Jane C. Waldbaum's thorough discussion and analysis of the Greek pottery found at the site. Most of it comes from the East Greek region, with a smaller amount attributed to the area of Corinth. She provides data on 560 registered vessels, mostly sherds, from the Leon Levy Archaeological Expedition to Ashkelon, as well as a dozen sherds from Phythian-Adams excavations at the site in 1921, all of which fills 211 pages. Each vessel is described in terms of its ware, decoration, find spot, registration number, and, when decorated, its parallels. Summary data are provided for many additional sherds that were not registered. Complementing this written description, each piece is reproduced in a color photograph and black-and-white line drawing. There is no doubt that this treatment will provide much of the basis for the discussion of the Greek role in the southern Levant for decades to come.

This brief note seeks to correct one small, but still significant misunderstanding of one aspect of one of the sherds discussed by Waldbaum. The sherd in question is

Jeffrey R. Zorn: Department of Near Eastern Studies, 409 White Hall, Cornell University, Ithaca, NY 14853, jrz3@ cornell.edu
Number 419, two conjoining pieces of an oinochoe related to North Ionian Wild Goat ware (Waldbaum 2011: 284 with illustrations on 285; Fig. 1). My focus here is part of the description of the helmeted warrior holding the raised thrusting spear in his right hand. Waldbaum's description reads: "Lower part of body covered by round shield facing out; quiver with arrows suspended above it." This is immediately suspect for two reasons. The first is that hoplites were heavy foot soldiers equipped with spear and sword and did not carry archery equipment. Second, to suspend a quiver of arrows from the shield would be awkward in the extreme.

In fact, what is actually depicted here is not the exterior of the shield but rather its interior. What is taken to be a quiver of arrows is part of the left forearm of the hoplite. The slightly curving line protruding up and forward from the top "arrow" is the soldier's thumb. The element that seems to be understood as a sort of a strap suspending the "quiver" is actually the hoplite's upper arm. Where the "quiver" joins this strap is the soldier's bent elbow.

Scenes depicting hoplites, either singly or in groups, are well attested on Greek pottery of the period around 600 в.C.E. In such scenes, the hoplite always carries his spear in the right hand, while the left hand carries his shield. This aspect of hoplite warfare is fundamental to understanding what is depicted on the Ashkelon sherd. The entire premise of the hoplite phalanx is that the shield carried in the left hand of one soldier protected the right side of the soldier to his left. When a hoplite faces left on a vase, the exterior of the shield is shown;

(c) 2014 American Schools of Oriental Research. BASOR 372 (2014): 35-38. 


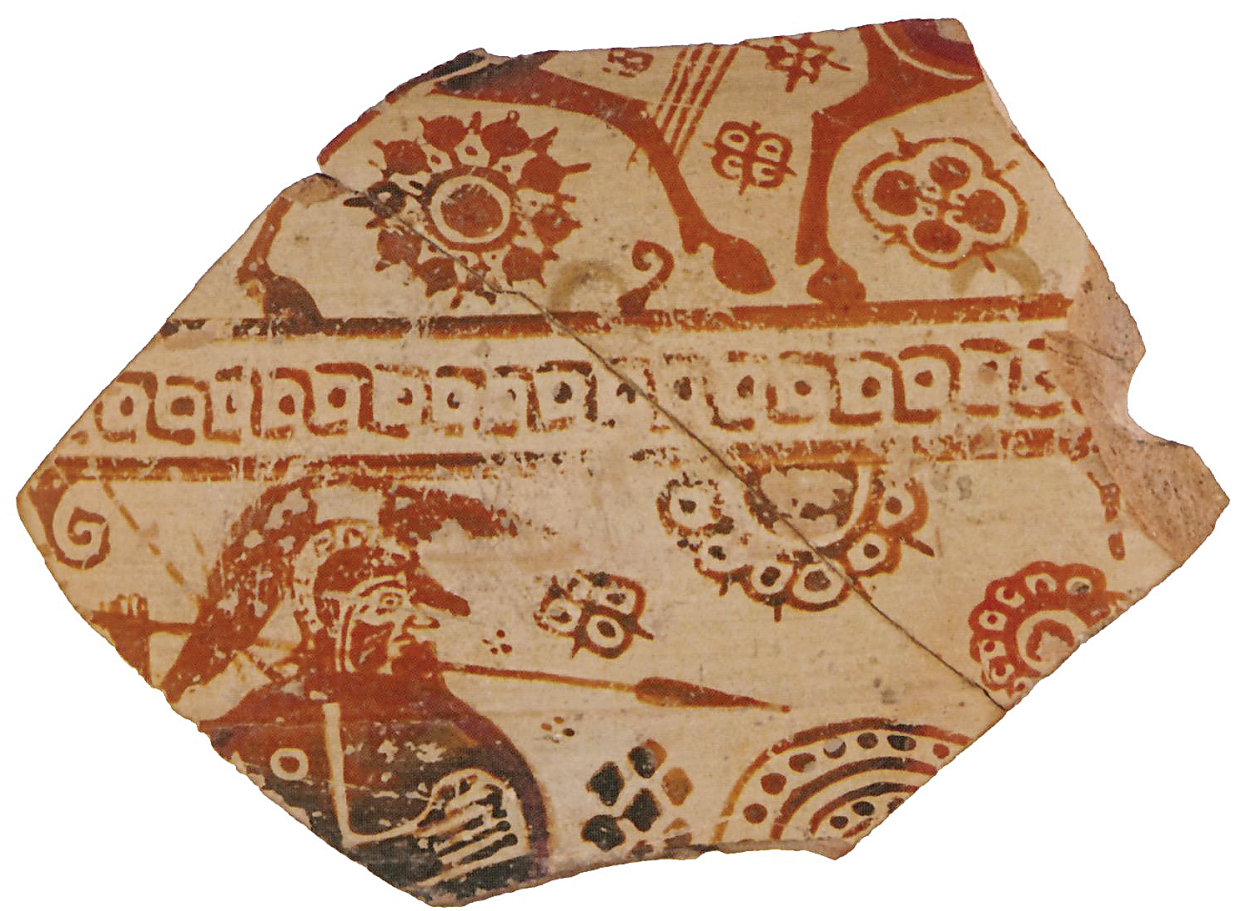

Fig. 1. Ashkelon hoplite sherd. Height 7.7 cm. Ashkelon excavation reg. no. A80/97.50.48.L453.B17.(59) + A40/90.50.49.L280.B334.(1). Courtesy of the Leon Levy Archaeological Expedition to Ashkelon (original photograph by Zev Radovan).

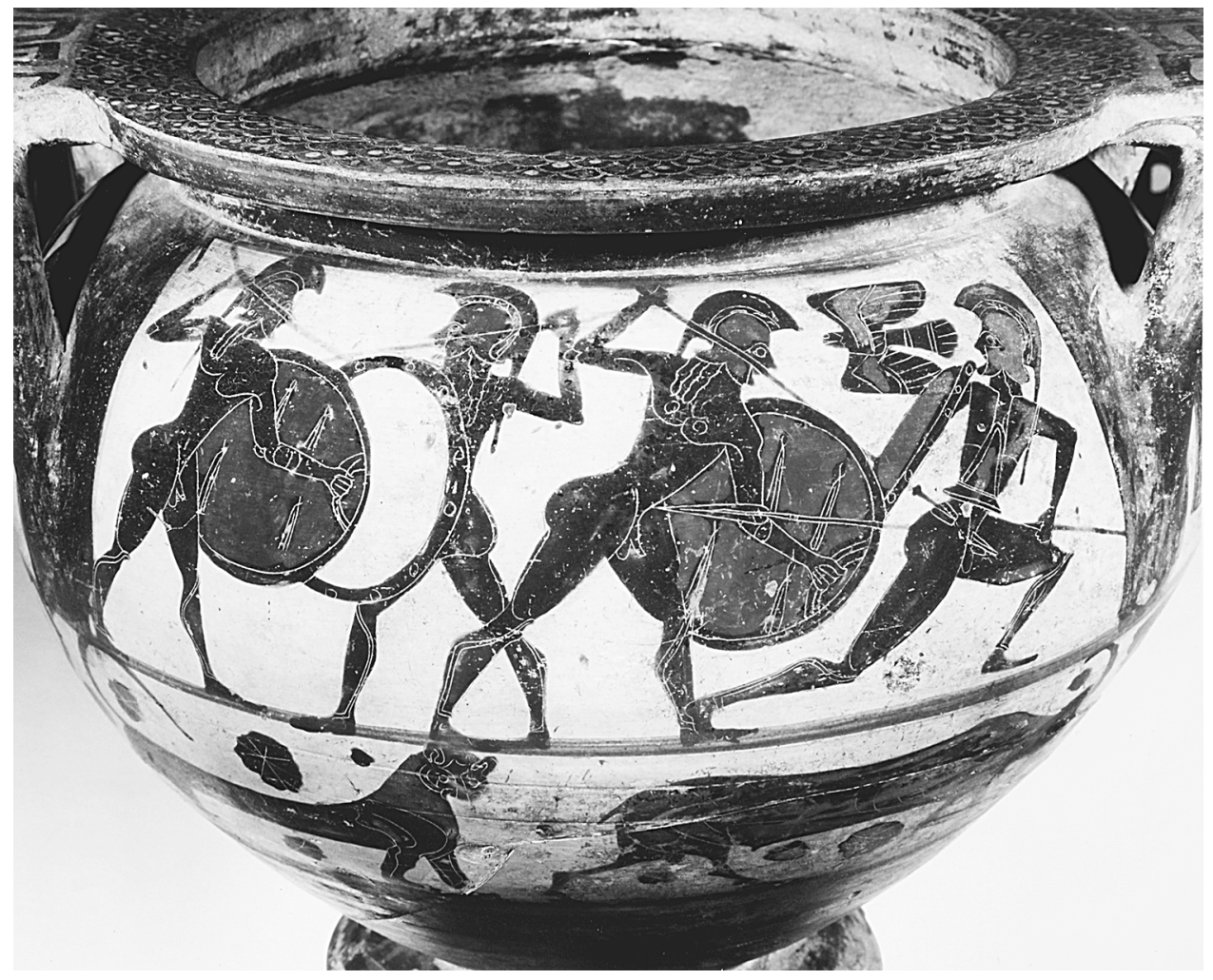

Fig. 2. Middle Corinthian krater showing interior view of shield. Height $29.3 \mathrm{~cm}$. Phoebe A. Hearst Museum of Anthropology 8/361. Image courtesy of Professor Andrew Stewart of the University of California, Berkeley. Permission to reproduce the image courtesy of the Hearst Museum. 
however, when a hoplite faces right, as in the case of the Ashkelon sherd, interior views depicting the hoplite's bent arm, hand, and the straps used to carry/support the shield are shown.

In a short note such as this, only a few examples of this practice will be cited. Perhaps the most famous example of hoplites in battle from about this era is the slightly earlier Chigi vase, a Middle Protocorinthian pitcher from an Etruscan tomb (D’Acunto 2013: pls. 1-5, 11, 12.1). In this scene, two groups of hoplites clash. The shields of those advancing from the right present an exterior view of the face of each shield. Interior views, showing bent arms and hands, are visible on those hoplites attacking from the left. Somewhat cruder, but still contemporary, depictions of the interiors of hoplite shields showing bent arm and hand are reproduced here as Figure 2. This krater (PAHMA 8/361; now in Berkeley), and a close parallel to it in Basel, are Middle Corinthian and attributed to the "Munich Painter" (Amyx 1988: Vol. 1:156; Vol. 3: pl. $60.1-2) .{ }^{1}$ On the Berkeley krater, the shield is extended out away from the body, allowing the artist to easily depict the complete supporting arm. In the case of the Ashkelon sherd, the hoplite's shield is centered on his body. Depictions showing the exterior surface of a shield centered on the body in this fashion are common, as in the Middle Protocorinthian MacMillan aryballos of the earlier part of the seventh century (Boardman 1998: 85; Fig. 3). Nearly centered shields showing an interior view are also present on the Chigi vase. However, even in these cases, the shield is just forward enough to show the complete bent arm. In extreme cases, where both the shield interior and left arm are depicted, as in the case of the hoplite shown on the left of the neck of a Parian amphora (Fig. 4), the left arm is bent and pressed tightly against the body and is placed too far to the right. Apparently showing such figures in true profile, where only part of the lower arm and hand might be visible, while the upper arm would be hidden behind the torso, was not to the liking of these painters. Notice how the upper torsos in the Berkeley vase and Parian amphora are shown in a full frontal view, not a profile.

The painter of the Ashkelon hoplite has also centered the shield. It seems, however, that his training or inclinations were in the style of silhouette painting of the Geometric and Subgeometric figure traditions; thus, he represents the shield as a silhouette. On the other hand, he attempts to follow one of the new traditions of his day by representing the left arm, as in the Middle Protocorinthian and Middle Corinthian examples cited here. Unfortunately for his effort, he was either unfamiliar with, or did

1 Amyx includes many other examples, too numerous to list here, of similar interior views of hoplite shields.

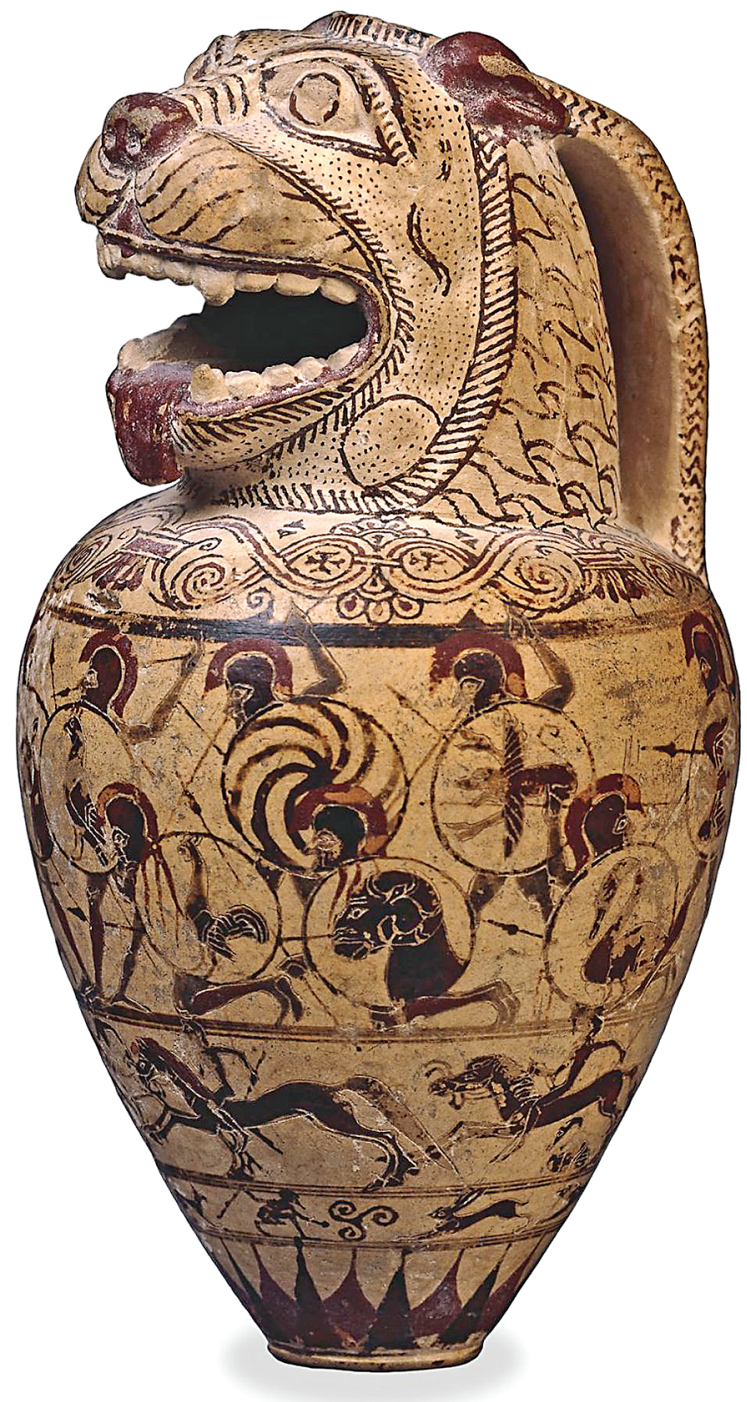

Fig. 3. Middle Protocorinthian MacMillan aryballos depicting hoplite combat. Note the exterior views of the centered shields. Height $6.8 \mathrm{~cm}$. British Museum GR 1889.4-18.1. Provenance uncertain, said to be from Thebes. http://www.britishmuseum.org/explore/highlights/ highlight_objects/gr/p/perfume_bottle_aryballos.aspx. Courtesy of the Trustees of the British Museum.

not use, incision or outline drawing (as in the Chigi vase and Parian amphora). He was thus incapable of properly representing overlapping in the multiple planes involved: the spear/right arm, head, left arm, and shield all seem to occupy a single plane. Moreover, the artist did not represent at all the twisted upper torso to which the left arm should be attached, further muddling his attempt. The end result is that the shield, in silhouette, seems to be in front of the body, which it cannot be since the (right) arm on that side is holding the spear. The shield must be on the other (left) side of the body, as normal, and the view must be the 


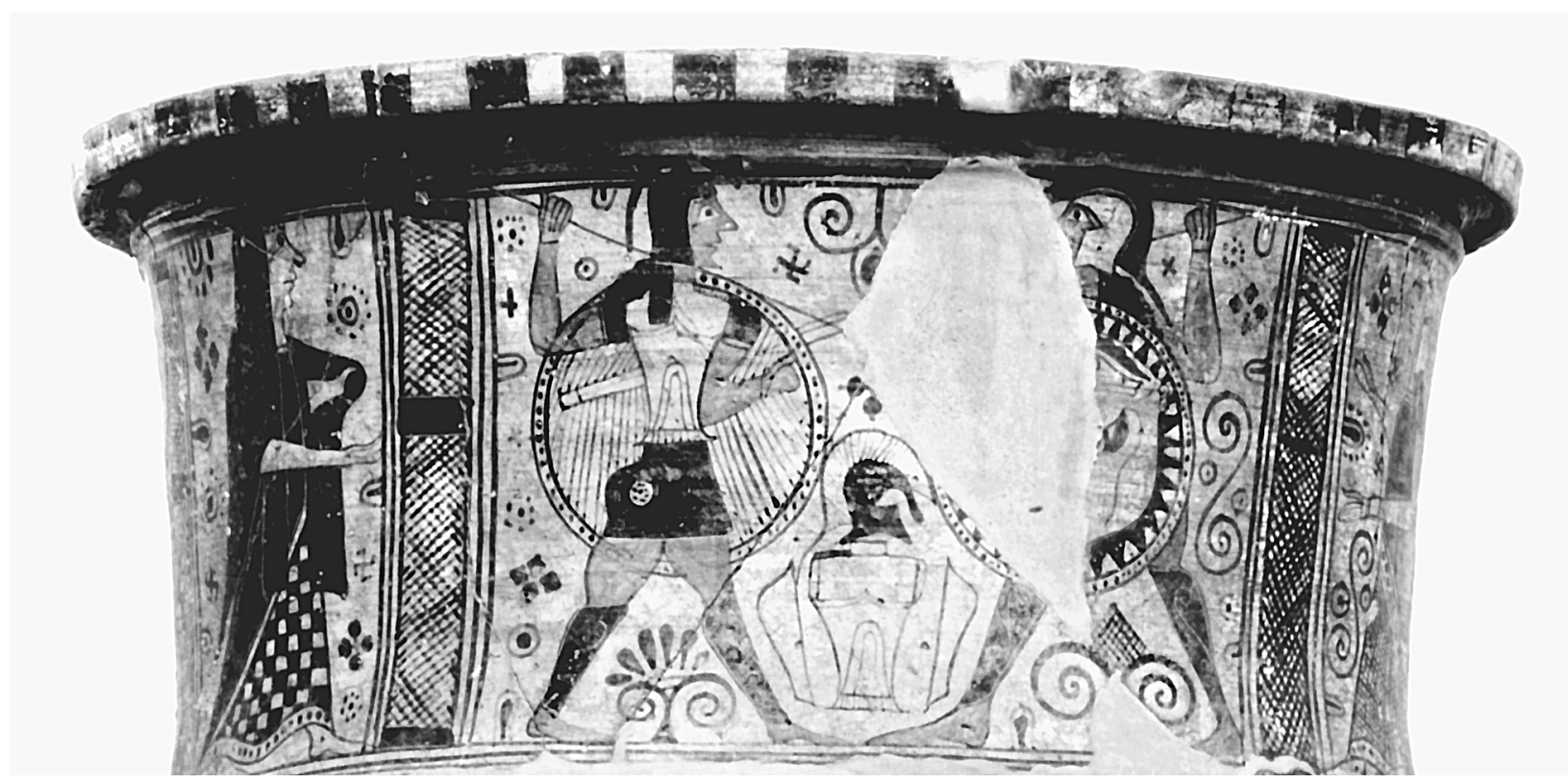

Fig. 4. Neck of a Parian amphora from Melos of the second half of the seventh century depicting a hoplite duel. Note the awkward position of the shield-bearing arm of the hoplite on the left. Height $97 \mathrm{~cm}$. Athens National Museum 3961. Courtesy of the Hirmer Fotoarchiv.

interior of the shield held by the left hand. Instead of representing the torso, and then the left arm in reserve outline, he has chosen to depict only the left arm. The arm thus appears to float in space in the middle of the shield. Finally, while the Ashkelon hoplite must be holding his shield in his left hand, this hand is represented more like the back of a right hand, rather than a view of the palm of the left hand. In sum, the artist's attempt to depict the interior view of the shield and arm by combining older and current forms of figure representation, while brave, was not wise and seems to have exceeded his ability.

The similarity between the depiction of the Ashkelon hoplite and those of the other vessels cited here is clear. The Ashkelon hoplite is not carrying a quiver suspended from the front of his shield. Instead, the audience is presented with an experimental and awkward view of the shield's interior and the hoplite's bodiless bent left arm and hand.

\section{Acknowledgments}

I thank Professors Andrew Stewart, Anthony M. Snodgrass, and Irene S. Lemos for discussing with me aspects of the Ash- kelon sherd and its parallels. All errors and omissions are solely the responsibility of the author.

\section{References}

Amyx, D.

1988 Corinthian Vase-Painting of the Archaic Period, Vols. 1 and 3. California Studies in the History of Art 25. Berkeley: University of California.

Boardman, J.

1998 Early Greek Vase Painting: 11th-6th Centuries BC: A Handbook. London: Thames and Hudson.

D'Acunto, M.

2013 Il mondo del vaso Chigi: Pittura, Guerra e società a Corinto alla metà del VII secolo a.C. Image \& Context 12. Berlin: De Gruyter.
Stager, L. E.; Master, D. M.; and Schloen, J. D.

2011 Ashkelon 3: The Seventh Century B.c. Final Reports of the Leon Levy Expedition to Ashkelon 3. Winona Lake, IN: Eisenbrauns.

Waldbaum, J. C.

2011 Greek Pottery. Pp. 127-338 in Ashkelon 3: The Seventh Century B.C. Final Reports of the Leon Levy Expedition to Ashkelon 3. Winona Lake, IN: Eisenbrauns. 